\title{
Africa and Nephrology: The Forgotten Continent
}

\author{
Ivor J. Katz Trevor Gerntholtz Sarala Naicker \\ University of the Witwatersrand, Johannesburg, South Africa
}

\section{Key Words}

Chronic kidney disease - Chronic kidney disease, prevention • End-stage renal disease $\cdot$ Africa $\cdot$ Nephrology • Brain drain · Health systems

\begin{abstract}
Chronic kidney disease (CKD) is not a priority on the health agenda in Africa and it remains a 'forgotten condition'. Most people in Africa do not have access to dialysis or transplantation, if they develop end-stage renal disease. Cardiovascular disease (CVD) and HIV/AIDS enjoy a more prominent profile as a serious cause of morbidity and mortality, but despite the clear links of CVD and HIV with CKD, there has been a failure to highlight the link between chronic illnesses like diabetes, hypertension and HIV/AIDS and both CKD and CVD. Management of chronic illnesses requires a functioning public health system and good links between primary and specialist care. Despite calls to establish CKD prevention programs, there are very few in Africa and they have not been integrated into existing primary healthcare systems. This is aggravated by shortages of both financial and human resources and failure to strengthen health systems managing chronic diseases. The result is that very few people in Africa with CKD are managed early or receive dialysis or transplantation. This article investigates some of the issues impacting on the recognition of CKD as a public health issue, and will also consider some factors which could make CKD a more prominent chronic disease in Africa.

Copyright $\odot 2010$ S. Karger AG, Basel
\end{abstract}

\section{Introduction}

Nephrologist to general population ratios in Africa are perhaps the lowest in the world making comprehensive delivery of renal care in this continent extremely challenging. In South Africa, one of the wealthiest nations on the continent, many people who develop end-stage renal disease (ESRD) are offered neither dialysis nor transplantation (renal replacement therapy - RRT) because of scarce resources and established protocols which accept only patients without significant co-morbid disease. [1, 2]. RRT was accessed by approximately 1.8 million people worldwide in 2004; less than $5 \%$ of the dialysis population was from sub-Saharan Africa [3]. The current dialysis treatment rate ranges from 421 per million population (pmp) in Egypt, to $<20 \mathrm{pmp}$ for most of Africa (and nil in many countries of sub-Saharan Africa); the corresponding figures for Japan being 1,940 pmp, USA 1,090 pmp and Germany $800 \mathrm{pmp}$. It is for this reason that Dirks and Levin [2] acknowledge the need for early detection and prevention of chronic kidney disease (CKD) in the developing world, but argue that in the short term there needs to be an increase in the provision of dialysis and transplantation and ways developed to limit the 'brain drain' to the developed world. Cardiovascular disease (CVD) has clear links with CKD and both share risk factors with common chronic illnesses like hypertension (HTN), diabetes (DM) and HIV. The management of CKD and CVD require a functioning public health sys-

\section{KARGER}

Fax +4161306 1234 E-Mail karger@karger.ch www.karger.com
Ivor J. Katz

University of the Witwatersrand

PO Box 92188, Norwood, Johannesburg 2117 (South Africa)

Tel. +27 83544 6364, Fax +27 119331514

E-Mail Ivor.Katz@wits.ac.za 
Table 1. Global health work force ${ }^{1}$

\begin{tabular}{|c|c|c|c|c|}
\hline & \multicolumn{2}{|l|}{ Physicians } & \multicolumn{2}{|l|}{ Nurses } \\
\hline & $\mathrm{n}$ & $\begin{array}{l}\text { density per } \\
10,000 \text { population }\end{array}$ & $\mathrm{n}$ & $\begin{array}{l}\text { density per } \\
10,000 \text { population }\end{array}$ \\
\hline \multicolumn{5}{|l|}{ WHO region } \\
\hline Africa & 150,714 & 2 & 792,853 & 11 \\
\hline Eastern Mediterranean & 532,486 & 10 & 777,077 & 15 \\
\hline South-East Asia & 849,324 & 5 & $1,995,190$ & 12 \\
\hline Western Pacific & $2,435,023$ & 14 & $3,466,342$ & 20 \\
\hline Europe & $2,825,271$ & 32 & $6,941,698$ & 78 \\
\hline Americas & $1,620,329$ & 19 & $4,095,757$ & 49 \\
\hline \multicolumn{5}{|l|}{ Income group } \\
\hline Low income & $1,163,269$ & 5 & $2,606,367$ & 11 \\
\hline Lower middle income & $2,894,455$ & 13 & $3,768,603$ & 17 \\
\hline Upper middle income & $1,673,117$ & 21 & $3,225,671$ & 41 \\
\hline High income & $2,682,262$ & 28 & $8,428,061$ & 87 \\
\hline Global & $8,413,147$ & 13 & $18,028,917$ & 28 \\
\hline
\end{tabular}

${ }^{1}$ World Health Statistics 2008 (http://www.who.int/whosis/whostat/2008/en/index.html).

tem, health workers and resources. One of the most important components of developing nephrology services to areas is the training of nephrologists who will prioritize renal disease and seek out patients who need care. This would require support from both private companies and government. Currently, the issue at hand is not whether Africa and nephrology are forgotten, but rather that CKD is not on the health agenda at all.

\section{CKD as a Problem in Africa}

The improved recognition of kidney disease globally can be attributed to some important developments which included redefining and reclassifying of CKD into a coherent conceptual model [4-6]. The KDOQI guidelines provide a methodology for the detection, assessment and management of all stages of CKD [4]. However, no reliable statistics for CKD exist for any African country. The credibility of statistics from many developing countries is questionable, but some experts have suggested a low incidence of $150 \mathrm{pmp}$ as the average for people who are receiving dialysis and transplants, i.e. ESRD [7]. This lower incidence more likely reflects poor data collection and fewer people receiving RRT in these countries. The challenge in Africa is to determine the epidemiology of CKD, and provide evidence that $\mathrm{CKD}$ is a public health problem.

\section{Nephrology and Nephrologists in Africa}

There remains a continuing 'brain drain' of healthcare workers from Africa to more affluent regions [8]. There are large rural areas of Africa that have no health professionals to serve these populations. Table 1 shows the distribution of healthcare workers in Africa and the developed world; Africa has the lowest numbers of physicians and nurses to serve its population. Table 2 shows the distribution of physicians and nephrologists in a spectrum of African countries and their corresponding rates of RRT. It is evident that there are no nephrologists in many parts of Africa [9]. In combination with the few nephrologists, RRT places an unaffordable financial burden on poor countries. The availability of RRT is very limited in much of sub-Saharan Africa due to high costs and shortage of skilled personnel. Most dialysis centers are situated in cities, placing a further burden on patients who often have to travel long distances to a dialysis center. Dialysis is often inefficient, due to technical and human resource limitations, with erratic availability of essential therapy such as erythropoietin, resulting in partial rehabilitation of the chronic dialysis patient. Transplantation is also only carried out in a few African countries: South Africa, Nigeria, Tunisia and Egypt, with most of the transplants being living donor transplants, except in South Africa where deceased donor transplants are carried out to a 
Table 2. Distribution of physicians, nephrologists and RRT in some African countries

\begin{tabular}{|c|c|c|c|c|c|c|c|c|c|}
\hline \multirow[t]{3}{*}{ Country } & \multicolumn{2}{|c|}{ Physicians } & \multicolumn{2}{|c|}{ Nephrologists } & \multicolumn{5}{|l|}{ RRT } \\
\hline & \multirow[t]{2}{*}{$\mathrm{n}$} & \multirow{2}{*}{$\begin{array}{l}\text { density/ } \\
10,000\end{array}$} & \multirow[t]{2}{*}{$\mathrm{n}$} & \multirow[t]{2}{*}{$\mathrm{pmp}$} & \multicolumn{2}{|l|}{$\mathrm{HD}$} & \multicolumn{2}{|c|}{ CAPD } & \multirow{2}{*}{$\frac{\mathrm{TP}}{\mathrm{n} / \text { year }}$} \\
\hline & & & & & $\mathrm{n}$ & $\mathrm{pmp}$ & $\mathrm{n}$ & pmp & \\
\hline Egypt & 179,900 & 24 & 500 & 6.5 & 33,000 & 421 & 45 & 0.3 & 500 \\
\hline Morocco & 1,303 & 11 & 135 & 4.5 & 4,860 & 162 & 30 & 1 & 13 \\
\hline Tunisia & 2,245 & $<1$ & 70 & 7 & 6,500 & 650 & 200 & 20 & 70 \\
\hline Nigeria & 34,923 & 3 & 70 & 0.6 & 1,000 & 8 & 0 & & 70 \\
\hline Ghana & 3,240 & 2 & 2 & 0.1 & 35 & 2 & 0 & & 0 \\
\hline Senegal & 594 & $<1$ & 2 & 0.2 & 50 & 4.2 & 26 & 1 & 0 \\
\hline Sudan & 11,083 & 3 & 25 & 0.7 & 1,610 & 46 & 111 & 3 & 74 \\
\hline Kenya & 4,506 & 1 & 15 & 0.5 & 260 & 7.5 & 30 & 1.2 & 10 \\
\hline Rwanda & 432 & $<1$ & 1 & & 0 & & 30 & 3.7 & 18 \\
\hline South Africa & 34,829 & 8 & 50 & 1.1 & 2,070 & 45 & 1,058 & 23 & 240 \\
\hline
\end{tabular}

$\mathrm{RRT}=$ Renal replacement therapy; $\mathrm{HD}=$ hemodialysis; CAPD = continuous ambulatory peritoneal dialysis; $\mathrm{TP}=$ transplants; $\mathrm{pmp}=$ per million population.

greater extent $(80 \%$ deceased donors and $20 \%$ living donors, respectively). Transplantation is limited by cost, donor shortages and lack of a brain-death law in most of sub-Saharan Africa. The transplant rate in Africa averages 4 pmp and is 9.2 pmp in South Africa $[9,10]$. Considering the poor access to RRT, we need to reconsider how we view CKD in Africa.

\section{CKD as a Chronic Disease}

Chronic illnesses, especially DM and HTN with infectious diseases like HIV/AIDS, require long-term management, and these illnesses have resulted in a rise of CVD and also CKD. Chronic diseases represent a huge proportion of human illness [11]. CKD has tended to be excluded from this group of chronic illnesses, mainly because until recently we have been unable to measure the significance of the problem. CKD also meets the criteria for consideration as a public health issue, the burden is high, it is getting larger and it is preventable like other chronic illnesses $[12,13]$.

Unfortunately, the greatest burden of non-communicable chronic disease is also felt by countries with a high burden of infectious communicable diseases [14-16], e.g. HIV can cause CKD in addition to its better known infective complications. Therefore, tackling CKD and integrating it into the management of chronic disease could potentially bring it to the attention of primary care clinicians.

\section{Strategies to Tackle CKD Burden}

Many economically advanced nations have achieved major reductions in the toll of chronic diseases, especially of CVD, which researchers tend to attribute more or less equally to prevention strategies and health services $[17,18]$. This appears to be both rational and cost-effective. We now have to ensure that the integration of prevention and treatment finds its way into the mainstream practices of kidney disease management. Effective solutions require comprehensive and integrated action at country level, led by governments, the private sector and involving local NGOs and key players at all levels of the health system. Figure 1 demonstrates its amalgamation with the public health levels of care and prevention strategies. This figure highlights the fact that any program hoping to tackle a chronic illness requires a well-functioning health system, including clear referral protocols and a sharing of clinical information. Importantly, horizontal integration of different curative and preventative services is imperative. Highlighting this link between CKD and CVD and demonstrating the clear association with the same primary chronic illnesses like DM, HTN and HIV/AIDS is part of the challenge to making governments and doctors 'remember' that nephrology is an important disease.

African countries must deal with the practical realities of limited resources and a double burden of infectious and non-communicable diseases. Integrated strategies, 
Fig. 1. Linking levels of care and prevention strategies for CKD. GFR = Glomerular filtration rate $\mathrm{ml} / \mathrm{min}$; ESRD = endstage kidney disease or CKD stage 5 . Adapted from KDIGO [13] and Cuban conceptual models [39].

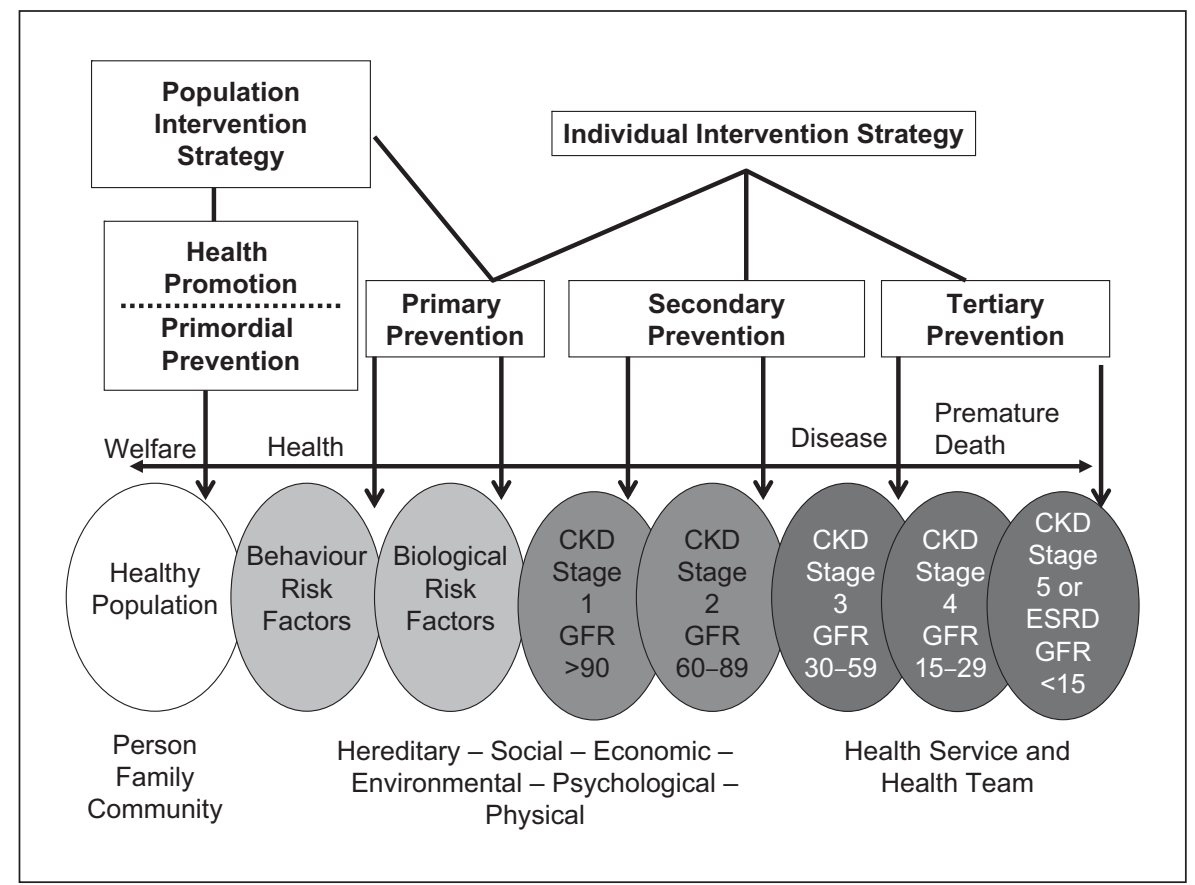

as proposed by the WHO [19], are always relevant for countries with budgetary and resource constraints. WHO has proposed an integrated stepwise approach to chronic disease prevention and control [19], including secondary prevention strategies once a country can afford them. The barriers affecting implementation in clinical practice need to be corrected and effort needs to be directed to improve communication between specialist units and primary care. The primary healthcare nurse has a critical role to play in tackling the problem of chronic diseases [20], and especially in Africa. The value and ability of the nurse to understand and detect CKD as a problem has been effective in the Soweto Chronic Disease Outreach Program [21].

\section{Health Systems and Resources}

Attempting to integrate a kidney disease focus within a chronic disease management program is challenging. People's health status and quality of life will not be improved solely by medication and technical advances, and thus healthcare systems have to move away from the current dominant model of 'find it and fix it' to a more integrated approach [22, 23], discussed above. Programs often rely on outside organizations and appropriate technologies to stimulate their development, but al- though non-governmental and private-for-profit organizations are important players in stimulating innovation, they cannot carry out the central activities of the public health sector [24]. Establishing intervention programs often requires many years from the time of conception to implementation and even more time to scale up [25].

The strengthening of health systems in developing countries remains a key challenge, especially in the wake of the existing epidemics of HIV and chronic diseases. Fragmentation of health systems, by developing parallel programs, can lead to chaos [26-28]. The energy and activism around HIV/AIDS should be joined with other chronic illness programs, providing an opportunity to strengthen and integrate health systems. CKD and HIV share similarities, their risk factors can be effectively detected and treated; their treatment is complex and they will require specialist support to ensure effective management at some point in the course of either disease. The major constraint with chronic illnesses is the life-long therapy required, often with multiple drugs. Another key challenge is insufficient financial investment into already weakened health systems. Although global funding has increased, adequate funding has been a challenge with scaling up of chronic disease programs. Even if there were adequate funding, the human resources required to provide treatment falls far short of what is required $[26,29]$. 
Fig. 2. Innovative care for chronic conditions framework. This model was developed by the World Health Organization based on the Wagner CICM model [20].

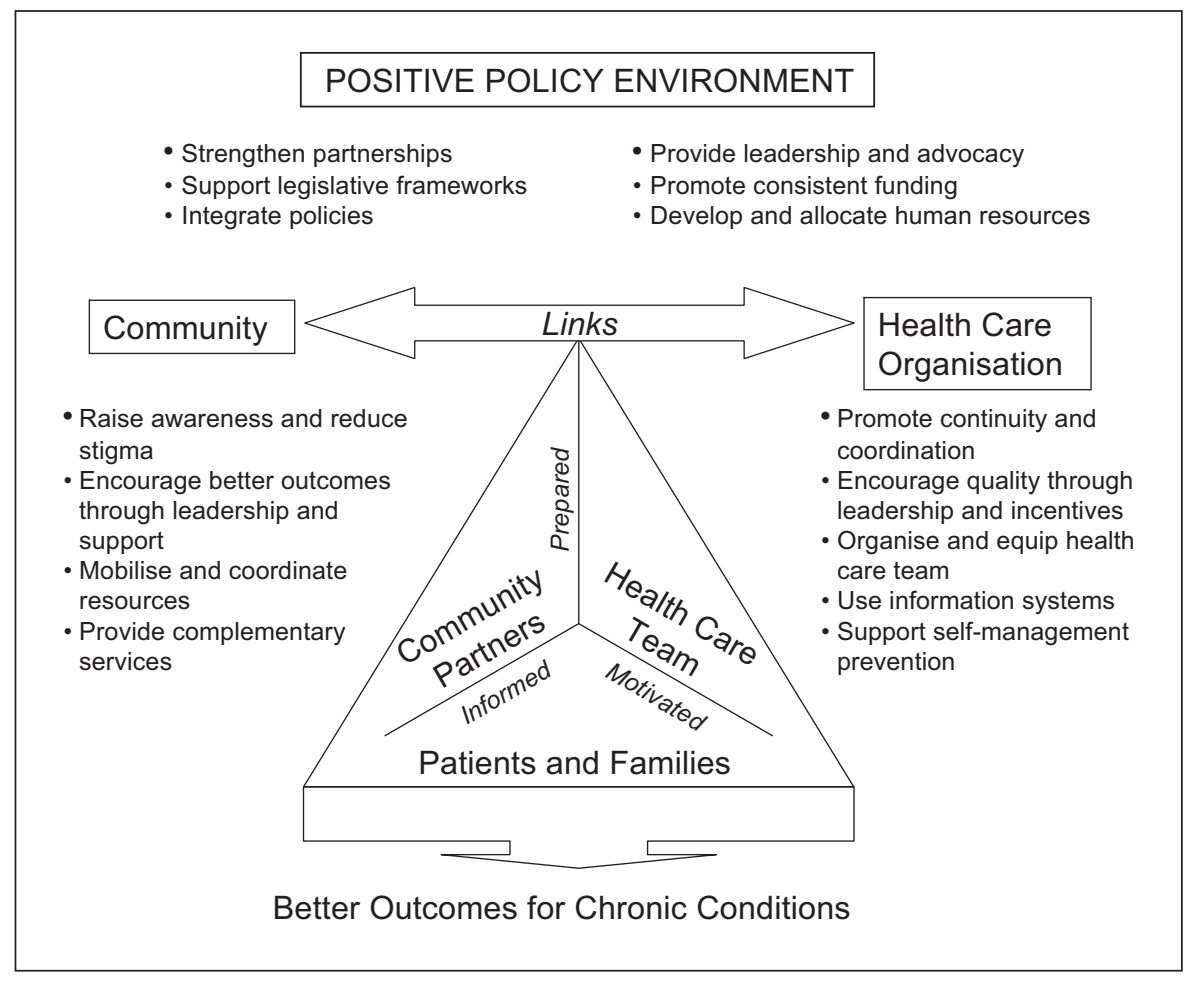

Table 3. Dialysis centers and patient numbers in private and public health sectors in South Africa

\begin{tabular}{lllll}
\hline Year & $\begin{array}{l}\text { Dialysis } \\
\text { centers }^{1}\end{array}$ & $\begin{array}{l}\text { Nephrolo- } \\
\text { gists }^{2}, \mathrm{n}\end{array}$ & $\begin{array}{l}\text { Patients on } \\
\text { hemodialysis, } \mathrm{n}\end{array}$ & $\begin{array}{l}\text { Patients on } \\
\text { peritoneal } \\
\text { dialysis, } \mathrm{n}\end{array}$ \\
\hline 2002 & 120 & 41 & 2,046 & 1,330 \\
2003 & 126 & 52 & 2,209 & 1,332 \\
2004 & 134 & 55 & 2,383 & 1,394 \\
2005 & 151 & 60 & 2,714 & 1,363 \\
2006 & 153 & 65 & 2,781 & 1,371 \\
2007 & 169 & 72 & 3,554 & 1,475 \\
2008 & 190 & 78 & 4,183 & 1,470 \\
\hline
\end{tabular}

Data collected from providers of dialysis in South Africa.

${ }^{1}$ Includes private and public dialysis centers.

${ }^{2}$ Includes general physicians working in nephrology.

Health system infrastructure is also inadequate. Such challenges cannot be reversed in the short term. There are models which can assist in the short- and long-term improvement of health systems. Models like the Wagner Chronic Illness Care Model [20] and WHO Innovative Care for Chronic Conditions [30] recognize these com- plexities, highlighting the need for adequate resources, appropriate protocols and systems, and for health workers and patients to work together (fig. 2).

\section{Scaling up Efforts for Managing Chronic Diseases and Kidney Disease}

Funding for RRT is primarily private in much of Africa, with the governments of only a few countries providing RRT for small number of patients (e.g. Mali, Mauritius, South Africa) $[9,10]$. In many African countries, chronic dialysis is not sustainable, with patients unable to afford dialysis beyond the first 2-3 months. In South Africa the small increase and better use of nephrologists, with financial backing of private dialysis companies and an environment provided by government, we has seen a growth in dialysis (table 3). The increase in dialysis numbers arises from a commitment in some areas to develop joint private public partnerships with government dialysis and transplant centers and private dialysis companies, but these are hampered by access to nephrologists. More recently, companies have started funding the training of nephrologists and together with ISN-COMGAN this will make a large difference in the future. 
However, in Africa issues are still hampered by dialysis rates as low as $45 \mathrm{pmp}$ for hemodialysis (HD) and 23 pmp for CAPD in South Africa; $46 \mathrm{pmp}$ for HD and 3 pmp for CAPD in Sudan, and 7.5 pmp for HD and 1.2 pmp for CAPD in Kenya compared to 421 pmp for HD and $0.3 \mathrm{pmp}$ for CAPD in Egypt, $650 \mathrm{pmp}$ for HD and 20 pmp for CAPD in Tunisia [9]. Availability of CAPD is limited in sub-Saharan Africa because of the high cost of dialysis fluids and a perception of a high rate of peritonitis. The average cost of HD in Africa is USD 100 per session. The annual costs of CAPD are equivalent to that of in-center HD.

The challenges for scaling up efforts and introducing new health interventions in developing countries are well described [31-33]. Constraints to the successful introduction of new interventions in the health system includes access to services, the affordability of the treatment, stigma of disease, unsatisfactory service delivery infrastructure, weak medication regulatory processes and supply systems, and the lack of good management of the required processes. Treatment has been made more affordable for chronic illnesses but the constraints to reaching universal coverage go beyond financial issues [31, 32]. A particular problem has been the lack of investment in people and infrastructure. The inadequate supply of skilled, motivated healthcare workers is now the primary limitation to scaling up treatment for chronic illnesses [34-37]. The problem has many dimensions and includes supply, migration of nurses and doctors, maldistribution, a skills mix imbalance, and also poor knowledge [37]. Given the skills shortage in Africa, the focus should be on investing in training health workers and preventing the 'brain drain' of nurses and doctors internationally. Response options include increasing the numbers of doctors and nurses, providing safe work environments and fairly paid jobs, and adopting delivery models with less reliance on these skills. However, models utilizing fewer doctors or nurses seem have attracted limited attention [38].

\section{Conclusions}

CKD needs to achieve the recognition as being a public health problem. Efforts have to be made to determine the extent of the problem in Africa by using existing relatively new techniques to screen and detect renal disease using community based screening programs and epidemiological studies. There needs to be an effort to integrate $\mathrm{CKD}$ as a chronic illness and ensure it is part of the conditions being tackled in the primary healthcare sec- tor. The growth of nephrology and renal disease is directly linked to the development of health systems to tackle chronic conditions and this includes the training and development of nephrology specialists amongst doctors and primary healthcare nurse clinicians.

The reality is that there is not enough money for healthcare in the developing world and provision of RRT is especially challenging in sub-Saharan Africa. The primary goal should be promotion of prevention strategies at all levels of healthcare in Africa; in those countries with a national program for RRT and with appropriate use of donor aid, a circumscribed chronic dialysis program, with as short a time on dialysis as possible, and increased availability of transplantation (both living related and cadaveric) should be the goal. Patients with renal disease should be referred to a nephrologist at an early stage so as to institute measures to retard progression and plan timely transplantation and/or dialysis; this is particularly important where related donors may be available.

Provision of RRT is especially challenging in subSaharan Africa. Nephrologists and physicians are faced with large numbers of ESRD patients, inadequate facilities, funding and support. Support from ISN and its COMGAN programs have gradually improved the capacity of physicians in many African countries to provide renal care. While prevention strategies are recognized as optimal therapy in managing CKD, it is still in its infancy in much of Africa, mainly due to lack of healthcare workers and funding.

Ultimately the governments and people of Africa have to create a stable environment to bring about these changes, and based on current evidence we still have a long way to go.

\section{Acknowledgements}

B. Braun, Fresenius, and National Renal Care in South Africa. 
$\checkmark 4$ National Kidney Foundation N: K/DOQI clinical practice guidelines for chronic kidney disease: evaluation, classification and stratification. Am J Kidney Dis 2002;39:S1S266.

$\checkmark 5$ Levey AS, Coresh J, Balk E, Kausz AT, Levin A, Steffes MW, Hogg RJ, Perrone RD, Lau J, Eknoyan G: National Kidney Foundation Practice Guidelines for Chronic Kidney Disease: evaluation, classification, and stratification. Ann Intern Med 2003;139:137-147.

-6 Levey A, Eckardt KU, Tsukamoto Y, Levin A, Coresh J, Rossert J, De Zeeuw D, Hostetter TH, Lameire N, Eknoyan G: Definition and classification of chronic kidney disease: a position statement from Kidney Disease: Improving Global Outcomes (KDIGO). Kidney Int 2005;67:2089-2100.

7 Barsoum RS: Epidemiology of ESRD: a worldwide perspective; in El Nahas M (ed): Kidney Disease in the Developing World and Ethnic Minorities. London, Taylor \& Francis, 2005, pp 1-13.

$\checkmark 8$ Eastwood JB, Conroy RE, Naicker S, West PA, Tutt RC, Plange-Rhule J: Loss of health professionals from sub-Saharan Africa: the pivotal role of the UK. Lancet 2005;365: 1893-1900.

9 El Matri A: End-stage renal disease in Africa; in AFRAN (ed): African Association of $\mathrm{Ne}$ phrology (AFRAN), Khartoum 2007.

10 Naicker S: End-stage renal disease in sub-Saharan and South Africa. Kidney Int 2003; 63(s83):119-122.

11 Horton R: The neglected epidemic of chronic disease Lancet 2005;366:1514.

12 Coresh J, Astor B, Greene T, Eknoyan G, Levey A: Prevalence of chronic kidney disease and decreased kidney function in the adult US population: Third National Health and Nutrition Examination Survey. Am J Kidney Dis 2003;41:1-12.

$\checkmark 13$ Levey A, Atkins R, Coresh J, Cohen EP, Collins AJ, Eckardt K-U, Nahas ME, Jaber BL, Jadoul M, Levin A, Powe NR, Rossert J, Wheeler DC, Lameire N, Eknoyan G: Chronic kidney disease as a global public health problem: approaches and initiatives - a position statement from Kidney Disease Improving Global Outcomes. Kidney Int 2007;72: 247-259.

14 Global Forum for Health Research: The 10/90 Report on Health Research 2001-2002. Geneva, Global Forum, 2002.

$\checkmark 15$ Abegunde D, Mathers CD, Adam T, Ortegon $\mathrm{M}$, Strong K: The burden and costs of chronic diseases in low-income and middle-income countries. Lancet 2007;307:1929-1938.
6 Strong K, Mathers C, Leeder S, Beaglehole R: Preventing chronic diseases: how many lives can we save? Lancet 2005;366:1578-1582.

17 Unal B, Critchley JA, Capewell S: Modelling the decline in coronary heart disease deaths in England and Wales, 1981-2000: comparing contributions from primary prevention and secondary prevention. BMJ 2005;331: 614.

18 Kuulasmaa K, Tunstall-Pedoe H, Dobson A, Fortmann S, Sans S, Tolonen H, Evans A, Ferrario M, Tuomilehto J: Estimation of contribution of changes in classic risk factors to trends in coronary-event rates across the WHO MONICA Project populations. Lancet 2000;355:675-687.

19 Epping-Jordan JE, Galea G, Tukuitonga C, Beaglehole R: Preventing chronic diseases: taking stepwise action. Lancet 2005;366: 1667-1671.

20 Epping-Jordan JE, Pruitt SD, Bengoa R, Wagner EH: Improving the quality of health care for chronic conditions. Qual Saf Health Care 2004;13:299-305.

21 Katz IJ: An Evaluation of a Chronic Disease Outreach Program (CDOP) - a primary care and tertiary care kidney and cardiovascular prevention, detection and management Program; in School of Public Health. Johannesburg, University of the Witwatersrand, 2009, pp 271.

22 Katz IJ: International Aid and the Formation of Successful Chronic Kidney Disease Prevention Programs (CKDPP); in Barsoum RS, El Nahas M (eds): Kidney Disease in Ethnic Minorities and the Developing World. New York, Dekker, 2005.

23 Epping-Jordan JE: Integrated approaches to prevention and control of chronic conditions. Kidney Int 2005;98:S86-S88.

24 Dodd R: Health and the Millennium Development Goals. Geneva, WHO, 2005, pp 84.

25 Katz IJ: International aid and medical practice in the less-developed world: doing it right, what can renal organizations learn? Kidney Int 2005;68:S60-S65.

26 McCoy D, Chopra M, Loewenson R, Aitken J-M, Ngulube T, Muula A, Ray S, Kureyi T, Ijumba P, Rowson M: Expanding access to antiretroviral therapy in sub-Saharan Africa: avoiding the pitfalls and dangers, capitalizing on the opportunities. Am J Public Health 2005;95:18-22.

27 Sanders DM, Chopra M: Implementing comprehensive and decentralised health systems: the quest for integrated care in postapartheid South Africa. Int J Integr Care 2001;1:2-10.
28 Sanders DM, Todd C, Chopra M: Confronting Africa's health crisis: more of the same will not be enough. BMJ 2005;331:755-758.

29 Rosen S, Sanne I, Collier A, Simon JL: Rationing antiretroviral therapy for HIV/AIDS in Africa: choices and consequences. PLoS Med 2005;2:e303.

30 World Health Organization: The innovative care for chronic conditions: building blocks for action; in Global Report. Geneva, WHO, 2002.

31 Victora CG, Hanson K, Bryce J, Vaughan JP: Achieving universal coverage with health interventions. Lancet 2004;364:1541-1548.

>32 Schneider H, Blaauw D, Gilson L, Nzapfurundi $\mathrm{C}$, Goudge J: Health systems and access to antiretroviral drugs for HIV in southern Africa: service delivery and human resource challenges. Reprod Health Matters 2006;14:12-23.

33 Gaziano TA, Galea G, Reddy KS: Scaling up interventions for chronic disease prevention: the evidence. Lancet 2007;370:1939-1946.

>34 Kober K, Van Damme W: Scaling up access to antiretroviral treatment in southern Africa: who will do the job? Lancet 2004;364: 103-107.

35 Hongoro C, McPake B: Human resources in health: putting the right agenda back to the front. Trop Med Int Health 2003;8:965-966.

36 Liese B, Blanchet N, Dussault G: The Human Resource Crisis in Health Services in SubSaharan Africa in Background Paper. Washington, The World Bank, 2003.

37 Chen LC, Evans TG, Anand S, Boufford JI, Brown H, Chowdhury M, Cueto M, Dare L, Dussault G, Elzinga G, Fee E, Habte D, Hanvoravongchai $\mathrm{P}$, Jacobs $\mathrm{M}$, Kurowski C, Michael S, Pablos-Mendez A, Sewankambo N, Solimano G, Stilwell B, de Waal A, Wibulpolprasert S: Human resources for health: overcoming the crisis. Lancet 2004;364:19841990.

38 Van Damme W, Kegels G: Health system strengthening and scaling up antiretroviral therapy: the need for context-specific delivery models (comment on H. Schneider et al.). Reprod Health Matters 2006;14:24-26.

-39 Almaguer M, Herrera R, Alfonso J, Magrans C, Mañalich R, Martinez A: Primary healthcare strategies for the prevention of endstage renal disease in Cuba. Kidney Int 2005; 68:S4-S10. 


\section{Editorial Comment}

M. El Nahas, Sheffield

This review by Katz and his colleagues highlights the plight of healthcare and nephrology in Africa. Africa is at the grip of a double-hit by communicable (HIV/AIDS, Malaria and Tuberculosis) and non-communicable disease (NCD) impacting on healthcare and its provisions. Whilst infectious diseases remain uncontrolled, the rising tide of NCD, such as diabetes and hypertension, is likely to increase the burden of CKD and the associated CVD. Urbanization in sub-Saharan Africa, with the associated obesity affecting both rich and poor, underlies the rapid rise in type 2 diabetes. It is expected that the rate of diabetes-related morbidity and mortality in this region, including CKD, could grow substantially [1]. Similarly, hypertension is often not diagnosed or treated. This was highlighted in the Heart of Soweto study that showed strong evidence that epidemiological transition in Soweto, South Africa, has broadened the complexity and spectrum of risk factors within the community [2]. Finally, Katz and co-authors express concern about the brain drain that is taking valuable and limited human resourc- es away from the continent. For that, an action plan was put forward by Eastwood et al. [3] in 2005. Five years on, I very much doubt that their proposals were taken on board.

Market forces are stronger than well-intentioned academic recommendations. The irony is that Ivor Katz, the author of the current review, a young, dynamic and very promising young South African nephrologist, left the continent a few months ago to work in Australia...

\section{References}

1 Mbanya JC, Motala AA, Sobngwi, E, et al: Diabetes in sub-Saharan Africa. Lancet 2010;375:2254-2266.

2 Sliwa K, Wilkinson D, Hansen C, et al: Spectrum of heart disease and risk factors in a back urban population in South Africa (the Heart of Soweto Study): a cohort study. Lancet 2008;371:915-922.

3 Eastwood JB, Conroy RE, Naicker S, et al: Loss of health professionals from sub-Saharan Africa: the pivotal role of the UK. Lancet 2005;365:1893-1900. 